\title{
The Role of Surface Passivation for Efficient and Photostable PbS Quantum Dot Solar Cells
}

Yiming $\mathrm{Cao}^{1,+}$, Alexandros Stavrinadis ${ }^{1,+}$, Tania Lasanta $^{1}$, David $\mathrm{So}^{1}$, Gerasimos Konstantatos $^{1,2 \star}$

${ }^{1}$ ICFO-Institut de Ciencies Fotoniques, The Barcelona Institute of Science and Technology, 08860 Castelldefels (Barcelona), Spain

${ }^{2}$ ICREA-Institució Catalana de Recerca i Estudis Avançats, Lluis Companys 23, 08010 Barcelona, Spain

${ }^{+}$These authors contribute equally to this work.

^e-mail: gerasimos.konstantatos@icfo.es.

For any emerging photovoltaic technology to become commercially relevant, both its power conversion efficiency and photostability are key parameters to be fulfilled. Colloidal quantum dot solar cells are a solution-processed, low-cost technology that has reached efficiency about $9 \%$ by judiciously controlling the surface of the quantum dots to enable surface passivation and tune energy levels. However, the role of quantum dot's surface on the stability of these solar cells has remained elusive. Here we report on highly efficient and photostable quantum dot solar cells with efficiencies of $9.6 \%$ (and independently certificated values of $8.7 \%$ ). As a result of optimised surface passivation and suppression of hydroxyl ligands-which are found to be detrimental for both efficiency and photostability-the efficiency remains within $80 \%$ after 
1,000 hours of continuous illumination at AM1.5G. Our findings provide insights on the role of the quantum dot's surface in stability and efficiency of quantum dot solar cells.

The solution processability, quantum confinement and inorganic nature of colloidal quantum dots (QDs) have made them one of promising materials for low cost, high efficiency, third generation photovoltaic technology ${ }^{1-6}$. Since the first reports ${ }^{1,2}$, a dramatic improvement in power conversion efficiency (PCE) has been achieved overpassing 9\% with $\mathrm{PbS}(\mathrm{Se})$ QDs leading the race as the material of choice ${ }^{5}$. This progress has been underpinned by the design of new heterostructures ${ }^{5-8}$, improved surface passivation schemes ${ }^{3,4}$ and advanced device architectures for more efficient charge collection and suppressed recombination ${ }^{9,10}$. While improvement in PCE of QD solar cells has been thoroughly sought after over the years, the photostability of this technology still remains an open challenge to further increase its technology readiness level, albeit initial promising results on low-performance PbS QD solar cells $^{11}$. The Achilles' heel of this photovoltaic technology is the surface of QDs, which remarkably impacts QDs' energy bands ${ }^{12}$, mid-gap states ${ }^{13}$, carrier transport $^{14}$ and stability ${ }^{15}$. Understanding the surface of QDs is a key to further advance solar cells in both performance and stability ${ }^{11,16-18}$.

High performance $\mathrm{PbS}$ QD solar cells rely on the presence of oleate surfactants for the passivation and stabilisation of the QDs upon synthesis (Fig. 1a). Great efforts and judicious ligand exchange strategies have since been developed to replace the long oleate ligands with short bidentate molecules (3-mercaptopropionic acid (MPA), 1,2-ethanedithiol (EDT), benzenedithiol (BDT) etc.) ${ }^{8,19,20}$ or atomic ligands based on halides ${ }^{3}$ to yield QD films with high carrier mobility and low trap-state density. In a recent study Zherebetskyy et al. ${ }^{21}$ elucidated the critical role of hydroxyl ligands on surface stabilisation of PbS QDs: while PbS (001) surfaces are most stable when neutral oleic acid covalently binds to lead ion without losing a proton, the $\mathrm{Pb}$-terminated (111) surface facets are grafted by steric deprotonated oleic 
acid along with small hydroxyl ligand $(\mathrm{OH})$ to preserve overall charge neutrality and surface energy minimisation (Fig. 1a). Most ligand exchange methodologies have focused on the removal of the oleate surfactants, yet the role of the hydroxylation has thus far remained elusive in solar cell efficiency and stability. We posited that the presence of those species may be a source of surface traps and instability in $\mathrm{PbS}$ QDs and thus sought to remove them. Herein we demonstrate that the native hydroxyl ligands on QD's surface are closely associated with performance and photostability of QD solar cells. By suppression of the hydroxide on PbS QD's surface through proper thermal annealing and a novel halide salt for ligand exchange reaction, we reduce mid-gap states, diminish charge recombination and improve both the photovoltaic performance and photostability of QD solar cells. The combination of lowtemperature fabrication, solution processing, PCE of 9.6\% (and independently certificated value of $8.7 \%$ ) and $>1,000$ hours of photostability makes a significant step forward in the technology readiness level of QD solar cells.

\section{The surface of $\mathrm{PbS}$ QDs and its role on device performance}

To test our hypothesis we developed QD solar cell structures that have led to high performance based on band-engineering ${ }^{5}$. Fig. $1 \mathrm{~b}$ shows a schematic structure and crosssectional image of a PbS QD solar cell made with the colloidal QDs solution with first exciton absorption peak at $930 \mathrm{~nm}$. The 120-nm-thick low-temperature processed $\mathrm{ZnO}$ nanoparticle film serves as an electron-accepting/hole-blocking layer, the 200-nm-thick tetrabutylammonium iodide (TBAI)-processed QD layer acts as a main charge generation layer and the 20-nm-thick EDT-processed QD layer as hole-extracting/electron-blocking layer ${ }^{5}$. The current density-voltage $(J-V)$ characteristic of QD solar cell, as displayed in Fig. 1c (blue curve), shows an open-circuit voltage $\left(V_{\mathrm{oc}}\right)$ of $0.46 \mathrm{~V}$, a short-circuit current $\left(J_{\mathrm{sc}}\right)$ of $17.37 \mathrm{~mA} \mathrm{~cm} \mathrm{~cm}^{-2}$ and a fill factor (FF) of 0.44 , yielding a PCE of $3.5 \%$. 
To pinpoint the origin of the low efficiency, we performed surface X-ray photoelectron spectroscopy (XPS) to probe the species on the surface of the QDs for the EDT- and TBAItreated QD layers. Fig. 2a shows the analysed S2p peak of the EDT-treated layer which can be deconvoluted to the sulfur signal of the PbS (wine curves) and of the EDT ligands. The latter is composed of two species: one attributed to bound thiolate on the $\mathrm{PbS}$ surface (orange curves) and the other to unbound thiol (SH) (green curves) ${ }^{22}$. This points to the presence of unbound thiols that have not reacted with the surface of the QDs shown in the inset of Fig. 2a. In order to probe the presence of the hydroxyl ligands and gain further insight on the surface construction of the QDs, we monitored the O1s peak, as shown in Fig. 2b. The O1s peak is dominated by a species at $531.0 \mathrm{eV}$ which has been assigned to the hydroxyl ligand (red curve) binding to $\mathrm{Pb}$ on (111) facet in $\mathrm{PbS}$ QD films ${ }^{21,23}$. Side peaks appearing at $532.2 \mathrm{eV}$ and 529.3 $\mathrm{eV}$ can be attributed to remaining oleate ligands that have not been washed out during the layerby-layer ligand exchange process or $\mathrm{CO}_{2}$ and $\mathrm{Pb}-\mathrm{O}$ molecules, respectively. The inset of Fig. $2 \mathrm{~b}$ illustrates the (111) surface re-constructed by the XPS data showing surface $\mathrm{Pb}$ atoms partially passivated by hydroxide and thiolate moieties. XPS was also performed on the iodidetreated QD layer. Here, we also focused on the O1s peak to monitor the presence of hydroxide. Fig. 2c shows a strong $\mathrm{Pb}-\mathrm{OH}$ species (red curve) along with side peaks attributable to oleate ligands or $\mathrm{CO}_{2}, \mathrm{~Pb}-\mathrm{O}$ and methanol $(533.8 \mathrm{eV})^{24}$. The inset of Fig. 2c illustrates the (111) surface with the $\mathrm{Pb}$ atoms binding to the various species. We attributed the poor performance of this cell therefore mainly to the poor thiolate binding and to the hydroxides that prevent complete passivation with the thiolate or iodide moieties.

\section{$\mathrm{OH}^{-}$suppression and improved passivation via thermal annealing}

We sought to circumvent this condition by a treatment that can activate unbound thiol moieties binding to the QD surface and desorb hydroxyl-ions. We hypothesized that further deprotonation of unbound thiols via reaction with hydroxyl ligands to form water could be 
achieved through proper thermal annealing. We therefore performed a mild-annealing treatment on the devices in a $\mathrm{N}_{2}$-filled glove box for $10 \mathrm{~min}$. As shown in Fig. 1c (olive curve), a significantly improved performance was achieved at an optimal $80^{\circ} \mathrm{C}$ annealing with a PCE reaching 6.4\%. (Supplementary Table 1 summarizes the photovoltaic performance of the QD solar cells annealed at $60,80,100$ and $120^{\circ} \mathrm{C}$ ). The external quantum efficiency (EQE) spectra of the devices are shown in Fig. 1d. The peak within 700-900 $\mathrm{nm}$ is caused by optical interference effects (Supplementary Fig. 1). Thermal annealing improves the EQE of PbS QD solar cells, which is not due to enhanced light absorption (Supplementary Fig. 2), suggesting thus improved charge generation/collection.

To elucidate the mechanisms at play upon annealing, we further elaborated on XPS analysis, following up on the non-annealed case. Fig. $2 \mathrm{~d}$ shows that annealing at the optimal temperature of $80{ }^{\circ} \mathrm{C}$ diminishes the unbound $\mathrm{SH}$ and intensifies the bound thiolate without loss of sulfur (Supplementary Table 2). The amount of bound thiolate in the annealed QD layer is close to the total amount of bound thiolate and unbound $\mathrm{SH}$ of the non-annealed counterpart (Supplementary Table 3), suggesting that unbound SH binds to QD surface upon the annealing. Such enhanced thiol-binding is followed by a significant suppression of the $\mathrm{Pb}-\mathrm{OH}$ signal and a new peak at $533.7 \mathrm{eV}$ in the $\mathrm{O} 1 \mathrm{~s}$ spectrum (Fig. 2e) attributable to $\mathrm{OH}$, pointing to a mechanism in which thiol-binding is caused by deprotonation of SH moieties via reaction with hydroxides that may subsequently form $\mathrm{HOH}$. This is further supported by the fact that the increased amount of bound thiolate (Supplementary Table 3) is comparable to the decreased amount of $\mathrm{Pb}-\mathrm{OH}$ species (Supplementary Table 4). The reverse effect of thiol-unbinding to the QD surface is observed when the QD layer is annealed at $120^{\circ} \mathrm{C}$, indicated by a decrease of thiol moieties and an increase of the $\mathrm{Pb}-\mathrm{OH}$ peak (Supplementary Fig. 3) ${ }^{25}$. A remarkable reduction in the $\mathrm{Pb}-\mathrm{OH}$ peak, yet not as large as in the case of EDT, appears also in the TBAItreated layer as shown in Fig. 2f. Quantitative XPS analysis in Supplementary Table 5 and 6 
and Supplementary Fig. 4 shows that, upon mild thermal annealing, the amount of decreased $\mathrm{Pb}-\mathrm{OH}$ is on par with the increase of iodide ions bound to $\mathrm{Pb}$ atoms of the QD surface. This indicates that the native hydroxide ligands in TBAI-processed QD layers can be replaced by iodide ions upon annealing. The slight increase of the detected iodide content upon annealing (Supplementary Table 5) may originate from the presence of originally unreacted excess iodide precursors or loosely bound iodide ions which thermally diffuse from the bulk of the film, also towards the top surface which is probed by XPS. This result points to further enhancement of performance may be within reach by further halogenation of the QD surface using excess halide treatments. Thermal annealing also facilitates more effective binding of iodides to the QDs which reflects upon stronger charge transfer to these moieties as evidenced by a corresponding increase of the lower binding energy components of the I3d peak (Supplementary Fig. 4). The insets in the Figs 2d-f describe the surface of the PbS QDs based on the XPS analysis.

The improved thiol and iodide binding results in lowering the energy levels of the QD layer due to the formation of the surface dipoles (Supplementary Fig. 5-7) in accordance with the model by Brown et $\mathrm{al}^{12}$. Mild annealing, through more effective surface ligand coverage and thereby surface dipole formation, leads therefore to optimized band alignment of the EDT- and TBAI-layers (Supplementary Fig. 6 and 7) and as a result to optimized solar cell performance. Control of surface passivation with diminished hydroxylation and improved thiolate and iodide ligand binding enabled by mild thermal annealing also leads to improved carrier mobility (Supplementary Fig. 8 and 9) most likely due to better passivation of traps and not by altering the quantum confinement of the QD film. This is supported by optical (Supplementary Fig. 2) and EQE spectra (Fig. 1d) that do not show red-shift and broadening as signatures of increased electronic coupling and loss of quantum confinement ${ }^{26,27}$. This is in agreement with a previous report by Gao et al. ${ }^{28}$, in which annealing of EDT-treated PbS films was reported to suppress deep traps in the temperature regime investigated herein without loss of quantum confinement. 
Annealing at a higher temperature of $120^{\circ} \mathrm{C}$ improves mobility further, in agreement with the report by Gao, yet it has adverse effects for the performance of solar cells due to the loss of ligands, the formation of deep traps and partial loss of quantum confinement ${ }^{28}$. Improved surface passivation via mild thermal annealing at $80{ }^{\circ} \mathrm{C}$ that has led to a remarkable increase in power conversion efficiency, further reflects upon longer carrier lifetimes and reduced recombination rates measured via transient photovoltage (TPV) and photocurrent (TPC) techniques (see Supplementary Fig. 10 and methods).

\section{EMII-treated PbS QDs}

Although TBAI has been successfully used in the past for high performance QD solar cells with $\mathrm{Au}$ anode ${ }^{5}$, our experiments yielded maximum PCE of $7.5 \%$ with a significant dispersion and average PCE of $6.5 \%$ (Supplementary Fig. 11). Herein, we present 1-ethyl-3methylimidazolium iodide (EMII, inset of Fig. 3a) as an alternative salt to be used for halidebased ligand exchange. The EMII has a cation with delocalized positive charge and less steric planar structure, compared to TBAI, which may facilitate more halide and less hydroxide binding on the QD surface. Fig. 3a shows the $J-V$ characteristics under AM1.5G conditions for the champion TBAI- and EMII-based solar cells. The EMII-processed QD solar cell annealed at $80{ }^{\circ} \mathrm{C}$ reaches PCE of $9.0 \%$ (average PCE of $8.0 \%$ ), with $V_{\text {oc }}$ of $0.56 \mathrm{~V}, J_{\mathrm{sc}}$ of $24.33 \mathrm{~mA} \mathrm{~cm}^{-}$ 2 and FF of 0.66 , which is superior to the TBAI-based counterpart with best PCE of $7.5 \%\left(V_{\text {oc }}\right.$ of $0.54 \mathrm{~V}, J_{\mathrm{sc}}$ of $22.87 \mathrm{~mA} \mathrm{~cm}^{-2}$ and FF of 0.61 ). A complete histogram of PCE for EMII- and TBAI-processed PbS QD solar cells (with first exciton peak at $930 \mathrm{~nm}$ ) are presented in Supplementary Fig. 11. An 8.8\% efficient solar cell was also sent to Newport for certification that was certified at $8.61 \%$ (Supplementary Fig. 12). Higher PCE values were achieved by using PbS QDs with an exciton peak at $850 \mathrm{~nm}$, which reached a best PCE of 9.6\%, with improved $V_{\text {oc }}$ of $0.63 \mathrm{~V}, J_{\mathrm{sc}}$ of $23.49 \mathrm{~mA} \mathrm{~cm}^{-2}$ and FF of $0.65(J-V$ characteristics, histogram of PCE and EQE are shown in Supplementary Fig. 13). Certified PCE by Newport for this class 
of PbS QD solar cells was measured at 8.77\% (Supplementary Fig. 14). It is worth noting that even at lower light intensities, the EMII-processed QD solar cells have photovoltaic performance superior to TBAI-processed counterparts (Supplementary Table 7).

Fig. $3 \mathrm{~b}$ shows the EQE of EMII-processed QD solar cell reaching $60 \%$ at the exciton peak, compared to $40 \%$ of TBAI-processed QD solar cell. TPV measurements yield a longer carrier lifetime of the EMII-treated solar cell, approximately by 50\%, compared to the TBAI-treated counterpart (Fig. 3c). This, along with the charge carrier density measured by TPC measurement (Supplementary Fig. 15), leads to an over two-fold decrease in recombination rate $\left(R_{\text {rec }}=n / \tau\right.$, where $n$ is the carrier density extracted by TPC and $\tau$ the carrier lifetime measured by TPV) for the EMII-based solar cell over the TBAI counterpart (Fig. 3c). This improvement in performance is followed by suppression of the hydroxide species (Fig. 3d) and the improved iodide passivation (Supplementary Fig. 16) on the surface of the EMII-treated QD layer, compared to the TBAI-based counterpart (Fig. 2f).

\section{Long-term photostability of QD solar cells}

While non-encapsulated EMII-processed solar cells are stable under storage in ambient conditions (Supplementary Fig. 17), similar to previous reports on TBAI-treated devices ${ }^{5}$, we herein are interested to study the stability of PbS QD solar cells under continuous simulated AM1.5G illumination and the effects of surface passivation on the photostability of those cells. Prior reports have recognized the deleterious effects of hydroxide species on the (photo)stability of other organic and inorganic PV technologies ${ }^{29-31}$, whereas alkyl-terminated ligands, such as oleic surfactants on QDs, can benefit the stability ${ }^{32}$. We tested the photostability of non-encapsulated QD solar cells soaked under simulated AM1.5G illumination in the $\mathrm{N}_{2}$-filled glove box, to eliminate additional degradation effects due to oxidation from the environment. As shown in Fig. 4, we found that the EMII-processed QD 
solar cells annealed at $80{ }^{\circ} \mathrm{C}$ show a remarkable photostability with PCE decaying to $80 \%$ of their initial values after $1,100 \mathrm{~h}$ of continuous illumination at open circuit condition (Note: the solar cells were removed from the glove box and tested in air). The non-annealed counterparts, in contrast, degrade to $80 \%$ of their initial PCE after $200 \mathrm{~h}$. Similarly, the TBAI-processed QD solar cells annealed at $80{ }^{\circ} \mathrm{C}$ decay to $80 \%$ of their initial PCE after $480 \mathrm{~h}$, inferior to the EMIIprocessed QD solar cells with $80{ }^{\circ} \mathrm{C}$ annealing, whereas the non-annealed counterparts decay after $140 \mathrm{~h}$. This degradation mechanism is remarkably accelerated at all cases when the stresstests are performed in ambient conditions. As shown in Supplementary Fig. 18, the EMIIprocessed QD solar cells annealed at $80{ }^{\circ} \mathrm{C}$ decay to $80 \%$ of initial PCE after $40 \mathrm{~h}$ of continuous light-soaking, still superior to the non-annealed counterparts whose PCE drop to $80 \%$ after 4 h.

In sum, remarkable improvement in the performance and photostability of $\mathrm{PbS}$ QD solar cells is reported employing surface passivation pathways that suppress the presence of hydroxide species on the QD surface. Based on the insights of our work, we envision further improvement by devising and refining passivation schemes that may entirely eliminate this species and therefore render QD solar cells an efficient and robust photovoltaic technology. 


\section{Methods}

Materials. PbO (99.999\%), oleic acid (90\%), 1-octadecene (90\%), trimethyldisilane (synthesis grade), $\mathrm{Zn}\left(\mathrm{CH}_{3} \mathrm{COO}\right)_{2} \cdot 2 \mathrm{H}_{2} \mathrm{O}$ ( $\left.\geqslant 98 \%\right)$, tetrabutylammonium iodide (98\%), 1-ethyl-3methylimidazolium iodide (97\%), 1,2-ethanedithiol $(\geqslant 98 \%)$ and $\mathrm{MoO}_{3}(99.97 \%)$ were purchased from Sigma-Aldrich. KOH ( $\geq 85 \%)$, reagent grade chloroform, toluene, methanol and acetonitrile were purchased from Panreac Quimica SLU. All chemicals were used as received, unless stated otherwise. 1 -octadecene was dried by heating at $80{ }^{\circ} \mathrm{C}$ under vigorous stirring for over $6 \mathrm{~h}$ and kept in a dry box along with trimethyldisilane. $\mathrm{Ag}(99.99 \%)$ and $\mathrm{Au}$ (99.999\%) pellets were purchased from Kurt J. Lesker.

Synthesis of colloidal PbS QDs. The synthesis of PbS QD colloidal solution with first exciton absorption peak at $930 \mathrm{~nm}$ was performed according to the literature ${ }^{10}$. A mixture of lead oxide ( $2 \mathrm{mmol}, 0.45 \mathrm{~g})$, oleic acid $(4 \mathrm{mmol}, 1.26 \mathrm{~mL})$, and 1-octadecene $(8 \mathrm{mmol}, 2.56 \mathrm{~mL})$ in a flask was heated and degassed under vacuum at $95^{\circ} \mathrm{C}$ for $12 \mathrm{~h}$, followed by adding $15 \mathrm{~mL}$ of 1 octadecene. The temperature was raised to $100^{\circ} \mathrm{C}$. The reaction was initiated by rapid injection of a mixture of trimethyldisilane $(1 \mathrm{mmol})$ and 1-octadecene $(10 \mathrm{~mL})$. The flask was allowed to gradually cool down to room temperature under stirring. QDs were purified in air by adding acetone, followed by centrifugation. The extracted QDs were dispersed in toluene with a concentration of $30 \mathrm{mg} / \mathrm{mL}$ for solar cell fabrication.

Synthesis of $\mathrm{ZnO}$ nanoparticles. The synthesis of $\mathrm{ZnO}$ nanocrystals was adapted from the literature ${ }^{33}$.

PbS colloidal solar cell fabrication. The ITO substrates were ultrasonically cleaned with solvents. The $\mathrm{ZnO}$ layer was fabricated by spin coating as-synthesised nanoparticle solution on the ITO substrate followed by $200{ }^{\circ} \mathrm{C}$ annealing for $15 \mathrm{~min}$ in air. The PbS QDs layer was fabricated by layer-by-layer spin coating methods in air. Briefly, the QD solution covered the 
substrate for each layer, followed by spinning at 2,500 r.p.m. for 20 s. 27 mM TBAI (10 g/L) or EMII (7 g/L) methanol solution covered the PbS layer for $30 \mathrm{~s}$ before spinning at 2,500 r.p.m. for $10 \mathrm{~s}$. The spinning substrate was washed by 10 drops of methanol and spun for $20 \mathrm{~s}$ to make film dry. The above process was repeated 12 times. To prepared $\mathrm{PbS}(\mathrm{EDT}) / \mathrm{PbS}$ (iodide)/ZnO/ITO films, the QD solution covered the TBAI- or EMII-treated $\mathrm{PbS}$ layer and spun at 2,500 r.p.m. for $20 \mathrm{~s}$. The PbS film was covered by $2.4 \mathrm{mM}$ EDT (0.02\% vol.) acetonitrile solution for $30 \mathrm{~s}$ before spun at 2,500 r.p.m. for $10 \mathrm{~s}$. The spinning substrate was washed by 10 drops of acetonitrile followed by spinning for $20 \mathrm{~s}$ to make film dry. The above process was repeated again to obtain two layers of EDT-treated $\mathrm{PbS}$. All the $\mathrm{PbS}$ films were stored in a $\mathrm{N}_{2}$-filled glove box $\left(\mathrm{H}_{2} \mathrm{O}<1 \mathrm{ppm}, \mathrm{O}_{2}<1 \mathrm{ppm}\right)$ overnight before thermally evaporating either with $10-\mathrm{nm} \mathrm{MoO}_{3}\left(0.1 \AA \mathrm{s}^{-1}\right), 40-\mathrm{nm} \mathrm{Au}\left(0.5 \AA \mathrm{s}^{-1}\right)$ and $150-\mathrm{nm} \mathrm{Ag}(2 \AA$ $\left.\mathrm{s}^{-1}\right)$ or with $100-\mathrm{nm} \mathrm{Au}\left(0.5 \AA \mathrm{s}^{-1}\right)$ by using a Kurt J. Lesker Nano 36 system at a base pressure lower than $1.0 \times 10^{-6}$ mbar. The solar cells, with an area of $0.0314 \mathrm{~cm}^{2}$, were taken out from the evaporator and transferred into the glove box for annealing. Solar cells reported in this study were not encapsulated.

Characterisations of $\mathbf{P b S}$ solar cells. $J-V$ characteristics of all solar cells were recorded in air by Keithley 2400 source meter under $100 \mathrm{~mW} \mathrm{~cm}^{-2}$ illumination conditions provided by Newport sol3A (class AAA) solar simulator. The light intensity was calibrated with a Newport $91150 \mathrm{~V}$ reference cell. Solar cells were stored in air for at least $10 \mathrm{~h}$ to yield best photovoltaic performances. For photostability tests, the solar cells were light soaked at open-circuit condition under simulated AM1.5G $100 \mathrm{~mW} \mathrm{~cm}^{-2}$ illumination in a $\mathrm{N}_{2}$-filled glove box or in ambient conditions as stated in the main manuscript. Before their $J-V$ characterisation, the solar cells were removed from the glove box and stored in air for half an hour. Thereafter, they were kept under dark in the glove box for one hour before continuing light soaking experiments to diminish the impacts of adsorbed water and oxygen on QDs. External quantum efficiency was 
measured with a lock-in amplifier (Stanford Research System SR830) under chopped monochromatic light generated by white light source from a xenon lamp passing through a Newport Cornerstone 260 monochromator. A home-made TPV/TPC setup was used to probe the $V_{\text {oc-dependent }}$ charge recombination and carrier density in QD solar cells ${ }^{4,34,35}$. The setup composes of a xenon arc lamp, a $637 \mathrm{~nm}$ laser (Vortran Stradus) and an Agilent 4000X oscilloscope. The lamp provides steady-state white bias light on solar cells. The light intensity was attenuated when needed by metal-mesh filters. The laser with a repetition rate of $10 \mathrm{~Hz}$ provides the small signal excitation. The pulse width was adapted between 100 and $300 \mu$ s and the intensity was controlled to keep the amplitude of the voltage transient below $20 \mathrm{mV}$. The oscilloscope records the data using the $1 \mathrm{M} \Omega(50 \Omega)$ input terminal for the TPV (TPC) measurements. A modified Prony algorithm was used to fit the exponential decay. Representative curves of the TPV-TPC measurements are shown in the Supplementary Fig. 19.

Fabrication and characterisation of field-effect transistor (FET). PbS QD FETs were fabricated on $p$-doped silicon substrate with $285 \mathrm{~nm}$-thick thermally-grown oxide layer. A 20 nm-thick PbS QD layer was deposited on the silicon substrate as described above. The drain contacts were fabricated by thermally evaporating $50 \mathrm{~nm}$-thick Au through masks (Ossila) with $1 \mathrm{~mm}$ channel widths and $30 \mu \mathrm{m}$ channel lengths. The gate was contacted by scratching the silica layer to expose the $p$-doped silicon. Individual transistors were isolated from neighbouring transistors by scratching away the deposited QD material. Annealing of FETs was performed in $\mathrm{N}_{2}$-filled glove box. Characterisations were performed in a probe station together with Agilent B1500A in air under dark. Representative FET characteristics are shown in the Supplementary Fig. 20. 
XPS and UPS characterisations. XPS and UPS measurements were performed with a with a SPECS PHOIBOS 150 hemispherical analyser (SPECS GmbH, Berlin, Germany) in ultra-high vacuum conditions $\left(10^{-10} \mathrm{mbar}\right)$. XPS measurements were performed with a monochromatic K $\alpha$ X-ray source $(1,486.74 \mathrm{eV})$ and UPS measurements with monochromatic HeI UV source $(21.2 \mathrm{eV})$. The XPS spectra are calibrated to $\mathrm{C} 1 \mathrm{~s}$ peak at binding energy of $284.8 \mathrm{eV}$. The deconvolution of the XPS spectra was performed by fitting a sum of Lorentzian-Gaussian functions (always with $80 \%$ Gaussian weighting) to the experimental data. For consistency, the full-width-at half-maximum (FWHM) of all Gaussian-Lorentzian functions was restricted to 1 $\pm 0.1 \mathrm{eV}$ with the exception of the analysis of the S2p spectra of the iodide treated QD samples which was best fitted using a single doublet with FWHM of $0.75 \mathrm{eV}$. Equal FWHM and peak positions $( \pm 0.05 \mathrm{eV})$ were assumed for all respective compounds within sample series (e.g. series of EDT-treated samples and series of TBAI-treated samples).

\section{Acknowledgements}

The research leading to these results has received funding from Fundació Privada Cellex, and European Community's Seventh Framework program (FP7-ENERGY.2012.10.2.1) under grant agreement 308997. We also acknowledge Financial support from the Spanish Ministry of Economy and Competitiveness (MINECO) and the "Fondo Europeo de Desarrollo Regional" (FEDER) through grant MAT2014-56210-R as well as the Severo Ochoa Programme for Centres of Excellence in R\&D (SEV-2015-0522). This work was also supported by AGAUR under the SGR grant (2014SGR1548). The authors thank Dr. Nichole Cates Miller for optical model simulating and measurement assistance, Dr. Helmut Mäckel for providing TPC/TPV setup and Quan Liu for measurement assistance. 


\section{Author contributions}

G. K. supervised the study. Y.C. and G.K. designed and directed this study and co-wrote the manuscript with feedback from all co-authors. Y.C. fabricated solar cells, characterized their photovoltaic performance, performed aging tests under AM1.5G illumination and analysed the XPS and UPS of QD solids. A.S. performed FIB imaging, synthesised colloidal PbS QDs, fabricated and characterised solar cells and analysed the XPS results. T.L. synthesised colloidal PbS QD. D.S. performed FET measurements.

\section{Additional information}

Supplementary information is available in the online version of the paper. Reprints and permissions information is available at www.nature.com/prints. Correspondence and request materials should be addressed to G.K.

\section{Competing financial interests}

The authors declare no competing financial interests.

\section{References}

1. Huynh, W. U., Dittmer, J. J. \& Alivisatos, A. P. Hybrid nanorod-polymer solar cells. Science 295, 2425-2427 (2002).

2. McDonald, S. A., Konstantatos, G., Zhang, S. G., Cyr, P. W., Klem, E. J. D., Levina, L. \& Sargent, E. H. Solution-processed PbS quantum dot infrared photodetectors and photovoltaics. Nat. Mater. 4, 138-142 (2005).

3. Tang, J., Kemp, K. W., Hoogland, S., Jeong, K. S., Liu, H., Levina, L., Furukawa, M., Wang, X. H., Debnath, R., Cha, D., Chou, K. W., Fischer, A., Amassian, A., Asbury, 
J. B. \& Sargent, E. H. Colloidal-quantum-dot photovoltaics using atomic-ligand passivation. Nat. Mater. 10, 765-771 (2011).

4. Ip, A. H., Thon, S. M., Hoogland, S., Voznyy, O., Zhitomirsky, D., Debnath, R., Levina, L., Rollny, L. R., Carey, G. H., Fischer, A., Kemp, K. W., Kramer, I. J., Ning, Z. J., Labelle, A. J., Chou, K. W., Amassian, A. \& Sargent, E. H. Hybrid passivated colloidal quantum dot solids. Nat. Nanotechnol. 7, 577-582 (2012).

5. Chuang, C.-H. M., Brown, P. R., Bulović, V. \& Bawendi, M. G. Improved performance and stability in quantum dot solar cells through band alignment engineering. Nat. Mater. 13, 796-801 (2014).

6. Ning, Z. J., Voznyy, O., Pan, J., Hoogland, S., Adinolfi, V., Xu, J. X., Li, M., Kirmani, A. R., Sun, J.-P., Minor, J., Kemp, K. W., Dong, H. P., Rollny, L., Labelle, A., Carey, G., Sutherland, B., Hill, I., Amassian, A., Liu, H., Tang, J., Bakr, O. M. \& Sargent, E. H. Air-stable n-type colloidal quantum dot solids. Nat. Mater. 13, 822-828 (2014).

7. Leschkies, K. S., Beatty, T. J., Kang, M. S., Norris, D. J. \& Aydil, E. S. Solar cells based on junctions between colloidal PbSe nanocrystals and thin $\mathrm{ZnO}$ films. ACS Nano. 3, 3638-3648 (2009).

8. Pattantyus-Abraham, A. G., Kramer, I. J., Barkhouse, A. R., Wang, X. H., Konstantatos, G., Debnath, R., Levina, L., Raabe, I., Nazeeruddin, M. K., Grätzel, M. \& Sargent, E. H. Depleted-heterojunction colloidal quantum dot solar cells. ACS Nano. 4, 3374-3380 (2010).

9. Rath, A. K., Bernechea, M., Martinez, L., de Arquer, F. P. G., Osmond, J. \& Konstantatos, G. Solution-processed inorganic bulk nano-heterojunctions and their application to solar cells. Nature Photon. 6, 529-534 (2012).

10. Rath, A. K., de Arquer, F. P. G., Stavrinadis, A., Lasanta, T., Bernechea, M., Diedenhofen, S. L. \& Konstantatos, G. Remote trap passivation in colloidal quantum 
dot bulk nano-heterojunctions and its effect in solution-processed solar cells. $A d v$. Mater. 26, 4741-4747 (2014).

11. Luther, J. M., Gao, J. B., Lloyd, M. T., Semonin, O. E., Beard, M. C. \& Noizk, A. J. Stability assessment on a 3\% bilayer $\mathrm{PbS} / \mathrm{ZnO}$ quantum dot heterojunction solar cell. Adv. Mater. 22, 3704-3707 (2010).

12. Brown, P. R., Kim, D., Lunt, R. R., Zhao, N., Bawendi, M. G., Grossman, J. C. \& Bulović, V. Energy level modification in lead sulfide quantum dot thin films through ligand exchange. ACS Nano. 8, 5863-5872 (2014).

13. Gao, J. B. \& Johnson, J. C. Charge trapping in bright and dark states of coupled PbS quantum dot films. ACS Nano. 6, 3292-3303 (2012).

14. Liu, Y., Gibbs, M., Puthussery, J., Gaik, S., Ihly, R., Hillhouse, H. W. \& Law, M. Dependence of carrier mobility on nanocrystal size and ligand length in $\mathrm{PbSe}$ nanocrystal solids. Nano Lett. 10, 1960-1969 (2010).

15. Moreels, I., Justo, Y., De Geyter, B., Haustraete, K., Martins, J. C. \& Hens, Z. Sizetunable, bright, and stable PbS quantum dots: a surface chemistry study. ACS Nano. 5, 2004-2012 (2011).

16. Tang, J., Brzozowski, L., Barkhouse, D. A. R., Wang, X. H., Debnath, R., Wolowiec, R., Palmiano, E., Levina, L., Pattantyus-Abraham, A. G., Jamakosmanovic, D. \& Sargent, E. H. Quantum dot photovoltaics in the extreme quantum confinement regime: The surface-chemical origins of exceptional air- and light-stability. ACS Nano. 4, 869$878(2010)$.

17. Ip, A. H., Labelle, A. J. \& Sargent, E. H. Efficient, air-stable colloidal quantum dot solar cells encapsulated using atomic layer deposition of a nanolaminate barrier. Appl. Phys. Lett. 103, 263905 (2013). 
18. Wang, H., Kubo, T., Nakazaki, J. \& Segawa, H. PbS colloidal quantum dot/ZnO-based bulk heterojunction solar cells with high stability under continuous light soaking. Phys. Status Solidi RRL 8, 961-965 (2014).

19. Luther, J. M., Law, M., Beard, M. C., Song, Q., Reese, M. O., Ellingson, R. J. \& Nozik, A. J. Schotty solar cells based on colloidal nanocrystal films. Nano Lett. 8, 3488-3492 (2008).

20. Koleilat, G. I., Levina, L., Shukla, H., Myrskog, S. H., Hinds, S., Pattantyus-Abraham, A. G. \& Sargent, E. H. Efficient, stable infrared photovoltaics based on solution-cast colloidal quantum dots. ACS Nano. 2, 833-840 (2008).

21. Zherebetskyy, D., Scheele, M., Zhang, Y. J., Bronstein, N., Thompson, C., Britt, D., Salmeron, M., Alivisatos, P. \& Wang, L.-W. Hydroxylation of the surface of PbS nanocrystals passivated with oleic acid. Science 344, 1380-1384 (2014).

22. Castner, D. G., Hinds, K. \& Grainger, D. W. X-ray photoelectron spectroscopy sulfur $2 p$ study of organic thiol and disulfide binding interactions with gold surfaces. Langmuir 12, 5083-5086 (1996).

23. Jo, C. H., Kim, J. H., Kim, J., Kim, J., Oh, M. S., Kang, M. S., Kim, M.-G., Kim, Y.H., Ju, B.-K. \& Park, S. K. Low-temperature annealed PbS quantum dot films for scalable and flexible ambipolar thin-film-transistors and circuits. J. Mater. Chem. C 2, 10305-10311 (2014).

24. Ammon, Ch., Bayer, A., Held, G., Richter, B., Schmidt, Th. \& Steinrück, H.-P. Dissociation and oxidation of methanol on Cu(110). Surf. Sci. 507, 845-850 (2002).

25. Luther, J. M., Law, M., Song, Q., Perkins, C. L., Beard, M. C. \& Nozik, A. J. Structural, optical, and electrical properties of self-assembled films of PbSe nanocrystals treated with 1,2-ethanedithiol. ACS Nano. 2, 271-280 (2008). 
26. Sandeep, C. S. S., ten Cate, S., Schins, J. M., Savenije, T. J., Liu, Y., Law, M., Kinge, S., Houtepen, A. J. \& Siebbeles, L. D. A. High charge-carrier mobility enables exploitation of carrier multiplication in quantum-dot films. Nat. Commun. 4, 2360 (2013).

27. Sandeep, C. S. S., Azpiroz, J. M., Evers, W. H., Boehme, S. C., Moreels, I., Kinge, S., Siebbeles, L. D. A., Infante, I. \& Houtepen, A. J. Epitaxially connected PbSe quantumdot films: controlled neck formation and optoelectronic properties. ACS Nano $\mathbf{8}$, 11499-11511(2014).

28. Gao, J. B., Jeong, S., Lin, F., Erslev, P. T., Semonin, O., E., Luther, J. M. \& Beard, M. C. Improvement in carrier transport properties by mild thermal annealing of $\mathrm{PbS}$ quantum dot solar cells. Appl. Phys. Lett. 102, 043506 (2013).

29. Rivaton, A., Chambon, S., Manceau, M., Gardette, J.-L., Lemaître, N. \& Guillerez, S. Light-induced degradation of the active layer of polymer-based solar cells. Polym. Degrad. Stab. 95, 278-284 (2010).

30. Razzell-Hollis, J., Wade, J., Tsoi, W. C., Soon, Y., Durrant, J. \& Kim, J.-S. Photochemical stability of high efficiency PTB7:PC70BM solar cell blends. J. Mater. Chem. A 2, 20189-20195 (2014).

31. Soria, F. A., Patrito, E. M. \& Paredes-Olivera, P. Oxidation of hydrogenated Si(111) by a radical propagation mechanism. J. Phys. Chem. C 116, 24607-24615 (2012).

32. Bansal, A. \& Lewis, N. S. Stabilization of Si photoanodes in aqueous electrolytes through surface alkylation. J. Phys. Chem. B 102, 4058-4060 (1998).

33. Beek, W. J. E., Wienk, M. M., Kemerink, M., Yang, X. N. \& Janssen, R. A. J. Hybrid zinc oxide conjugated polymer bulk heterojunction solar cells. J. Phys. Chem. B 109, 9505-9516 (2005). 
34. O’Regan, B. C., Scully, S., Mayer, A. C., Palomares, E. \& Durrant, J. The effect of $\mathrm{Al}_{2} \mathrm{O}_{3}$ barrier layers in $\mathrm{TiO}_{2} / \mathrm{Dye} / \mathrm{CuSCN}$ photovoltaic cells explored by recombination and DOS characterization using transient photovoltage measurements. J. Phys. Chem. $B$ 109, 4616-4623 (2005).

35. Shuttle, C. G., O’Regan, B., Ballantyne, A. M., Nelson, J., Bradley, D. D. C., de Mello, J. \& Durrant, J. R. Experimental determination of the rate law for charge carrier decay in a polythiophene: fullerene solar cell. Appl. Phys. Lett. 92, 093311 (2008). 
Figure 1 | Surface of PbS QDs and performance of QD solar cells. a, Schematic pictures of $\mathrm{PbS}$ quantum dots with oleic surfactants showing (001) facet stabilized by weakly adsorbed oleic acid and (111) facet by deprotonated oleic ligands together with hydroxide groups. b, Schematic structure and cross-sectional FIB image of $\mathrm{PbS}$ solar cells with $\mathrm{MoO}_{3} /$ metal anode. c, $J$ - $V$ characteristics of non- and $80^{\circ} \mathrm{C}$-annealed QD solar cells under simulated AM1.5G 100 $\mathrm{mW} \mathrm{cm}{ }^{-2}$ illumination condition. d, EQE spectra of non- and $80{ }^{\circ} \mathrm{C}$-annealed QD solar cells. The vertical dot line indicates the first exciton peak of the QD film in solar cells. 
Figure 2 | XPS of non- and $80^{\circ} \mathrm{C}$-annealed QD layers processed with EDT and TBAI. a, Signal from S2p of non-annealed QD layer processed with EDT. b, Signal from O1s of nonannealed QD layer processed with EDT. c, Signal from O1s of non-annealed QD layer processed with TBAI. d, Signal from S2p of $80^{\circ} \mathrm{C}$-annealed QD layer processed with EDT. e, Signal from O1s of $80^{\circ} \mathrm{C}$-annealed QD layer processed with EDT. f, Signal from O1s of 80 ${ }^{\circ} \mathrm{C}$-annealed QD layer processed with TBAI. To show the relative intensity, the fitting peak of $\mathrm{S} 2 \mathrm{p}_{3 / 2}$ from $\mathrm{PbS}$ (wine curves) in a and $\mathbf{d}$ is respectively normalized to one; the fitting peak of $\mathrm{O} 1 \mathrm{~s}$ assigned to $\mathrm{Pb}-\mathrm{OH}$ (red curves) in $\mathbf{b}$ and $\mathbf{c}$ is respectively normalized to one, and the intensity of $\mathrm{O} 1 \mathrm{~s}$ in $\mathbf{e}$ and $\mathbf{f}$ is respectively normalized to $\mathbf{b}$ and $\mathbf{c}$. The insets mainly illustrate the impacts of annealing upon $\mathrm{Pb}$-thiolate $(\mathbf{a}, \mathbf{d})$ and $\mathrm{Pb}-\mathrm{OH}(\mathbf{b}, \mathbf{e})$ on the surface of EDT-treated QDs and upon $\mathrm{Pb}-\mathrm{OH}(\mathbf{c}, \mathbf{f})$ on the surface of TBAI-treated QDs. 
Figure 3 | EMII-processed PbS QD solar cells. a, $J$ - $V$ characteristics of $80{ }^{\circ} \mathrm{C}$-annealed QD solar cells (Au anode) processed with TBAI and EMII under simulated AM1.5G $100 \mathrm{~mW} \mathrm{~cm}{ }^{-2}$ illumination. The inset shows the molecular structures of TBAI and EMII. b, EQE spectra of the $80{ }^{\circ} \mathrm{C}$-annealed QD solar cells processed with TBAI and EMII. c, $V_{\text {oc}}$-dependent carrier lifetime ( $\tau$, open circle) and recombination rates $\left(R\right.$, solid circle) of the $80{ }^{\circ} \mathrm{C}$-annealed QD solar cells processed with TBAI (olive colour) and EMII (royal colour). d, The relative intensity of $\mathrm{O} 1 \mathrm{~s}$ of $80{ }^{\circ} \mathrm{C}$-annealed QD layer processed with EMII to the non-annealed counterpart with TBAI in Fig 2c. The inset illustrates further reduced hydroxyl ligands on the surface of annealed QDs processed with EMII. 
Figure 4 | Photostability assessment of QD solar cells. a, Evolution of PCE. b, Evolution of $V_{\text {oc. }}$ c, Evolution of $J_{\text {sc. }}$ d, Evolution of FF. The average (symbols) and stand deviation (error bars) were calculated from a sample of four to eight solar cells. Processed with EMII and TBAI, the non- and $80{ }^{\circ} \mathrm{C}$-annealed PbS QD solar cells with $\mathrm{Au}$ anode were soaked under simulated AM1.5G $100 \mathrm{~mW} \mathrm{~cm}{ }^{-2}$ illumination and simultaneously suffered $60{ }^{\circ} \mathrm{C}$ thermal aging in the $\mathrm{N}_{2}$-filled glove box at open circuit conditions. All the QD solar cells are neither encapsulated nor equipped with ultraviolet filter. 